\title{
Modelamiento físico en geotecnia aplicado a la docencia
}

\author{
Julián Alfonso Tristancho-Ortiz \\ Facultad de Ingeniería, Universidad Distrital Francisco José de Caldas, Bogotá, Colombia. jatristanchoo@udistrital.edu.co
}

\begin{abstract}
Resumen - En el presente documento se plantea el uso de la centrifuga geotécnica como herramienta didáctica. Se presenta un marco referencial sobre el uso de prácticas de laboratorio dentro de la didáctica de los cursos de ingeniería, y su importancia según el modelo Kolb de aprendizaje. Se describe luego la solución completa del modelamiento en centrifuga de un problema típico de geotecnia basado en la estructura de un túnel poco profundo en suelo blando. En la parte final se hace una discusión sobre las ventajas y desventajas que este tipo de laboratorios presenta frente a las técnicas de laboratorios virtuales.
\end{abstract}

Palabras Clave- Centrifuga geotécnica, Modelo Kolb, Prácticas de laboratorio, Túneles poco profundos.

Recibido: 15 de octubre de 2016. Revisado: 17 de enero de 2017.

Aceptado: 27 de enero de 2017.

\section{Physical modelling in geotechnics applied to education}

Abstract - This document poses the use of geotechnical centrifuge as a didactic tool. A framework of teaching of engineering courses of the use of this equipment in laboratory practices is presented. Also is presented then Kolb learning model and its interconnection with laboratory practices. The complete solution in centrifuge modeling a typical problem geotechnics based on the structure of a shallow tunnel in soft ground is then described. At the end of a discussion of the advantages and disadvantages between the "real" laboratories and "virtual" laboratories it is done.

Keywords - Geotechnical centrifuge, Kolb model, Laboratories practices, shallow tunnels.

\section{Introducción}

Los ingenieros en su desempeño profesional tienen que manipular materiales, energía o información. La organización ABET (ABET son las siglas en inglés de Accreditation Boardfor Engineering and Technology. La ABET es una entidad no gubernamental, sin ánimo de lucro dedicada a la acreditación universitaria de ciencias aplicadas, ingeniería y tecnología. ABET ha acreditado unos 3100 programas de 660 instituciones en 23 países), define como las principales habilidades que un ingeniero debe tener al momento de salir de la universidad como las mostradas en la Tabla 1

Las técnicas tradicionales de enseñanza-aprendizaje son centradas en el profesor (clases magistrales, solución de problemas teóricos, prácticas de laboratorio definidas en cuanto a sus metodologías y resultados, etc.), relegando al estudiante a un estado pasivo. Con una metodología de enseñanza tradicional es muy difícil lograr cumplir las habilidades esperadas según la Tabla 1.
Tabla 1.

Habilidades esperadas de formación para un ingeniero

\begin{tabular}{ll}
\hline \multicolumn{1}{c}{ Habilidades cognitivas } & \multicolumn{1}{c}{ Habilidades profesionales } \\
\hline Aplicar los conocimientos & $\begin{array}{l}\text { Funcionar en equipos } \\
\text { multidisciplinarios }\end{array}$ \\
\hline $\begin{array}{l}\text { Diseñar y realizar experimentos, } \\
\text { analizar e interpretar datos }\end{array}$ & $\begin{array}{l}\text { Responsabilidad ética y } \\
\text { profesional }\end{array}$ \\
\hline $\begin{array}{l}\text { Diseñar un sistema, componente, o } \\
\text { proceso para satisfacer necesidades } \\
\text { teniendo en cuenta sus impactos }\end{array}$ & Comunicarse efectivamente \\
\hline $\begin{array}{l}\text { Identificar, formular y solucionar } \\
\text { problemas de ingeniería }\end{array}$ & $\begin{array}{l}\text { Comprender los posibles } \\
\text { impactos de las soluciones de } \\
\text { ingeniería }\end{array}$ \\
\hline $\begin{array}{l}\text { Usar las técnicas, habilidades, e } \\
\text { instrumentos modernos de ingeniería }\end{array}$ & $\begin{array}{l}\text { Compromiso con el aprendizaje } \\
\text { durante toda la vida }\end{array}$ \\
\hline
\end{tabular}

Fuente: Adaptado de [1]

Los estudios realizados en [2], demostraron que los procesos pasivos de enseñanza (metodología tradicional) llegan a niveles de retención inferiores al $50 \%$. Un proceso de enseñanza activa obtiene niveles superiores al $70 \%$. La enseñanza activa vincula al estudiante de manera permanente en su formación. Estudios adicionales como los desarrollados en [3-6], han demostrado lo expuesto [2]. La enseñanza activa fortalece el desarrollo de habilidades para diseñar y realizar experimentos, incluyendo un proceso o componente, capacidad para identificar y formular problemas de ingeniería, correspondientes todos a las habilidades cognitivas necesarias de un ingeniero.

En los estudios desarrollados por [7], se concluyó que para aprender algo, este nuevo conocimiento debe ser trabajado o procesado a partir de: una experiencia directa y concreta o bien de una experiencia abstracta. Este nuevo conocimiento es apropiado una vez se elabora de manera reflexiva o experimentando de forma activa. En la Fig. 1 se muestran las diferentes etapas para el aprendizaje óptimo según el modelo Kolb. 


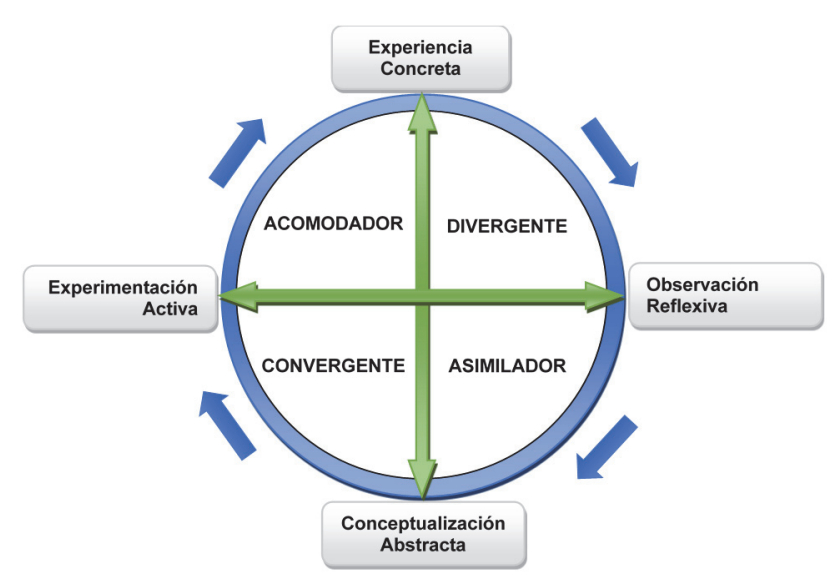

Figura 1. Modelo de aprendizaje de Kolb. Fuente: Adaptado de [8]

Según el modelo de Kolb cada estudiante se especializa en un tipo de aprendizaje: Activo, Reflexivo, Teórico y Pragmático. Según [9] los laboratorios de ingeniería permiten que los estudiantes atraviesen las diferentes etapas de aprendizaje y ofrecen a cada tipo de aprendizaje un campo de acción, siempre y cuando se diseñe de manera adecuada. También identificaron que el principal problema de los laboratorios diseñados de manera tradicional impide que los estudiantes creen o desarrollen una metodología para la extracción de datos o diseño de un nuevo dispositivo. Es por eso que [9] plantean que los objetivos que todo laboratorio debe cumplir para lograr su cometido formativo son las mostradas en la Tabla 2

\subsection{El uso didáctico de los modelos físicos en la geotecnia}

El suelo es una estructura formada por tres componentes principales en tres estados diferentes: partículas sólidas, agua líquida y aire en estado gaseoso. La descripción del comportamiento mecánico de este tipo de estructura es compleja, pues se tiene un modelo mecánico de contacto de partículas o estructura que determina el comportamiento del sistema particulado, un modelo hidráulico para el movimiento del agua y un modelo psicométrico para el aire. Cada modelo pese a que tiene leyes individuales, están interrelacionados generando complejos modelos termohidromecánicos que describen el comportamiento del sistema completo. El uso de un sistema de ecuaciones diferenciales parciales acopladas con la capacidad de modelar adecuadamente el suelo de manera implícita conlleva mucho trabajo matemático y generalmente son necesarias una gran cantidad de supuestos o reducciones, para llegar a ecuaciones "manejables". Los modelos numéricos en cambio tienen la posibilidad de resolver estos sistemas de ecuaciones diferenciales de manera eficaz pero aislando al estudiante de la realidad física del suelo. Además el conjunto de modelos numéricos implementados dependen de una gran cantidad de parámetros que caracterizan los suelos y condiciones especiales para determinar los rangos validos de análisis.

El uso del modelamiento físico en la geotecnia como herramienta para resolver problemas complejos o en la docencia está ampliamente documentada. Autores como [10], reporta un importante incremento del diseño de un tipo de centrifuga especializado en la docencia. Esto originado en la miniaturización de la instrumentación, aparición de cámaras digitales de alta resolución y disminución de los costos en los sistemas electrónicos de adquisición y procesamiento. Entre las principales ventajas del modelamiento físico en el ámbito de la educación en geotecnia se tiene:

1. En los modelos físicos es posible ver mecanismos geotécnicos complejos no lineales o difíciles de visualizar de otra manera;

Tabla 2.

Objetivos que deben ser desarrollados en una práctica o laboratorio de docencia

\begin{tabular}{|c|c|c|}
\hline ID & ÁREA & OBJETIVO \\
\hline 1 & Instrumentación & $\begin{array}{l}\text { Motivar la correcta selección de sensores, } \\
\text { instrumentación y/o software para hacer la } \\
\text { medición de las variables físicas }\end{array}$ \\
\hline 2 & Modelos & $\begin{array}{l}\text { Identificar claramente las ventajas y limitaciones } \\
\text { que poseen los modelos teóricos usados, con } \\
\text { respecto a los resultados del mundo real }\end{array}$ \\
\hline 3 & Experim & $\begin{array}{l}\text { Diseñar el procedimiento experimental que debe } \\
\text { ser seguido para obtener los resultados o } \\
\text { mediciones deseadas }\end{array}$ \\
\hline 4 & $\begin{array}{l}\text { Análisis de } \\
\text { datos }\end{array}$ & $\begin{array}{l}\text { Diseñar el método de extracción adecuada de la } \\
\text { información necesaria desde los datos } \\
\text { capturados, tener la capacidad de interpretar los } \\
\text { resultados, identificando los problemas y sacar } \\
\text { conclusiones acordes a un nivel científico } \\
\text { adecuado }\end{array}$ \\
\hline 5 & Diseño & $\begin{array}{l}\text { Tener la capacidad de crear procedimientos, } \\
\text { metodologías o nuevos dispositivos que permitan } \\
\text { obtener las mediciones necesarias }\end{array}$ \\
\hline 6 & $\begin{array}{l}\text { Realimentación } \\
\text { positiva }\end{array}$ & $\begin{array}{l}\text { Tener la capacidad de aprender de los errores } \\
\text { cometidos durante la prueba, debidos a equipos, } \\
\text { metodología, construcción, etc. Permitiendo usar } \\
\text { esos errores para plantear soluciones más } \\
\text { adecuadas o mejoras de su experimento }\end{array}$ \\
\hline 7 & Creatividad & $\begin{array}{l}\text { Usar su pensamiento creativo para la solución de } \\
\text { problemas a partir de las herramientas } \\
\text { disponibles y extrapolarlo a un problema del } \\
\text { mundo real }\end{array}$ \\
\hline 8 & Psicomotor & $\begin{array}{l}\text { Demostrar competencia en el uso y selección de } \\
\text { diferentes herramientas y recursos de ciencias } \\
\text { aplicadas e ingeniería }\end{array}$ \\
\hline 9 & Seguridad & $\begin{array}{l}\text { Identificar claramente los riesgos y problemas } \\
\text { ambientales que se podrían tener durante la } \\
\text { práctica, mitigando sus posibles efectos }\end{array}$ \\
\hline 10 & Comunicación & $\begin{array}{l}\text { Tener la capacidad de comunicar efectivamente } \\
\text { el método usado para la práctica, con sus } \\
\text { resultados y conclusiones }\end{array}$ \\
\hline 11 & $\begin{array}{l}\text { Trabajo en } \\
\text { equipo }\end{array}$ & $\begin{array}{l}\text { Trabajar efectivamente en equipos, incluyendo } \\
\text { estructuración individual y responsabilidad } \\
\text { conjunta, asignados roles y responsabilidades. }\end{array}$ \\
\hline 12 & $\begin{array}{l}\text { Ética en el } \\
\text { laboratorio }\end{array}$ & $\begin{array}{l}\text { Comportamiento ético en la presentación de } \\
\text { resultados, incluyendo el reporte de la } \\
\text { información objetivamente. }\end{array}$ \\
\hline 13 & $\begin{array}{l}\text { Conciencia } \\
\text { sensorial }\end{array}$ & $\begin{array}{l}\text { Desarrollar el sentido común originario del uso } \\
\text { de sus sentidos para realizar juicios de ingeniería, } \\
\text { sobre comportamientos y problemas }\end{array}$ \\
\hline
\end{tabular}

Fuente: Adaptado de [9] 
2. Mediante la observación de los modelos físicos, en los estudiantes generan el desarrollo de la intuición y sentido físico de los mecanismos básicos que rigen el comportamiento de las estructuras geotécnicas;

3. Los modelos físicos pueden ser probados hasta el colapso, lo que permite a los estudiantes visualizar los mecanismos de falla que generalmente no es posible ver en las sesiones de laboratorio;

4. Con el análisis de los resultados obtenidos los estudiantes pueden encontrar las diferencias entre el comportamiento del modelo y los previstos por la teoría, pudiendo identificar las limitaciones de uno u otro modelo (modelo físico vs modelo numérico)

\subsection{Modelación en centrífuga geotécnica}

La modelación física está dirigida a predecir el comportamiento que sufrirá un prototipo mediante la reproducción de un modelo con propiedades físicas y mecánicas muy similares a las de la obra [11]. Ante la imposibilidad de utilizar en la modelación centrífuga modelos con las mismas dimensiones a las del prototipo, el modelo diseñado es una versión a escala reducida de la obra a escala natural. Una característica especial de la modelación geotécnica es la necesidad de replicar el comportamiento del suelo en términos de su resistencia y rigidez. Los suelos, se caracterizan porque sus propiedades mecánicas presentan un comportamiento no lineal y éstas dependen principalmente de los esfuerzos efectivos de confinamiento y de la historia de esfuerzos de dicho material. La centrífuga geotécnica permite incrementar la aceleración gravitacional a un modelo de suelo en orden a producir los mismos esfuerzos efectivos en el modelo y prototipo. La relación 1/1 (modelo /prototipo) en los esfuerzos aumenta la similitud de los modelos geotécnicos y permite a su vez obtener datos precisos que ayudan a resolver muchos problemas geotécnicos complejos [12].

Con la centrífuga geotécnica se pueden reproducir los mismos esfuerzos efectivos en el modelo y prototipo. El modelado en centrífuga genera que los parámetros de escala estén relacionados entre modelo y prototipo por la aceleración centrifuga aplicada al modelo.

En la Tabla 3 se presentan las características principales de la centrifuga didáctica de docencia, utilizada en el presente estudio para la realización de los ensayos. Esta centrifuga se puede categorizar como pequeña con respecto a otras existentes en el mundo.

\subsection{Planteamiento del problema didáctico}

Como herramienta pedagógica para la demostración del comportamiento del suelo sobre procesos de desconfinamiento y sus efectos en estructuras civiles de superficie, se plantea el escenario de un túnel construido en suelos blandos con las dimensiones mostradas en la Fig. 2. El prototipo tiene una construcción del tipo de cimentación con losa generalizada. Se plantea que el suelo es una arcilla blanda saturada consolidada con una presión constante de $100 \mathrm{KPa}$ (esfuerzo de preconsolidación). Se propone que para realizar el modelo se use como suelo una composición de Caolín y Bentonita, con una composición de $60 \%$ y $40 \%$ respectivamente.

\section{Metodología}

\subsection{Escalamiento del modelo}

Las dos restricciones fundamentales para el escalamiento del prototipo son las limitaciones geométricas y de aceleración que presenta la máquina centrifuga. Otro factor muy importante es el efecto que la escala puede tener sobre la instrumentación del modelo o las condiciones de frontera del mismo [13], a mayor escala del modelo el efecto del tamaño del grano del suelo es más significativo, los parámetros a medir en el suelo son más pequeños y sensibles al ruido de los instrumentos. A menor escala se tiene mayor dificultad en la construcción del modelo y el escalamiento del tiempo se hace mucho más "lento". El planteamiento del problema indica un proceso cuasi estático.

Tabla 3.

Principales características centrífuga geotécnica para modelos pequeños - Universidad de Los Andes.

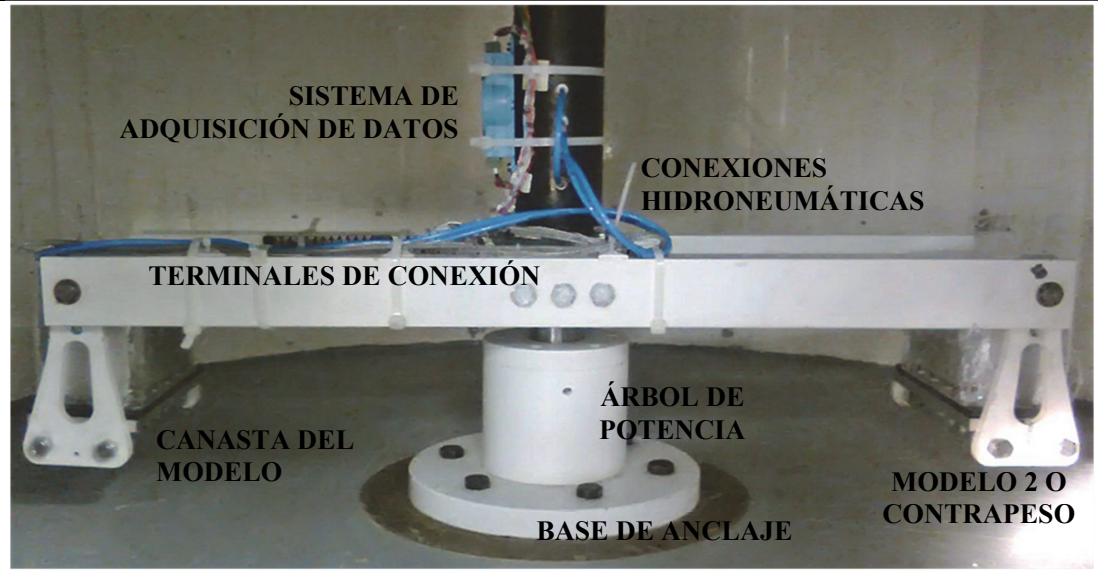

\begin{tabular}{lr}
\multicolumn{2}{c}{ DIMENSIONES } \\
\hline Distancia eje plataforma & $56.5 \mathrm{~cm}$ \\
Longitud del rotor & $1.5 \mathrm{~m}$ \\
Diámetro sala centrifugación & $1.7 \mathrm{~m}$ \\
Altura sala de centrifugación & $70 \mathrm{~cm}$ \\
Longitud plataforma & $17.5 \mathrm{~cm}$ \\
Largo plataforma & $13.5 \mathrm{~cm}$ \\
Altura libre & $10.0 \mathrm{~cm}$ \\
\hline \multicolumn{2}{c}{ RENDIMIENTO } \\
\hline Masa del modelo (max) & $5000 \mathrm{~g}$ \\
Acel. máxima (5000 gr) & $400 \mathrm{G}$ \\
Potencia Nominal & $3 \mathrm{HP}$ \\
\hline \multicolumn{2}{c}{ CONEXIONES CON EL MODELO } \\
\hline Canales análogos medición & 40 \\
\hline Contactos potencia & 36 \\
\hline Canales hidroneumáticos & 4
\end{tabular}

Fuente: Los autores 


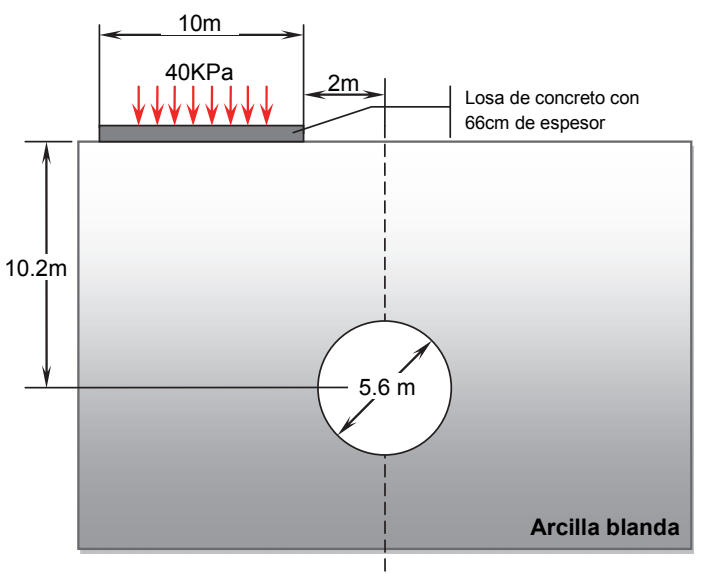

Figura 2. Dimensiones del prototipo problema. Fuente: Los Autores

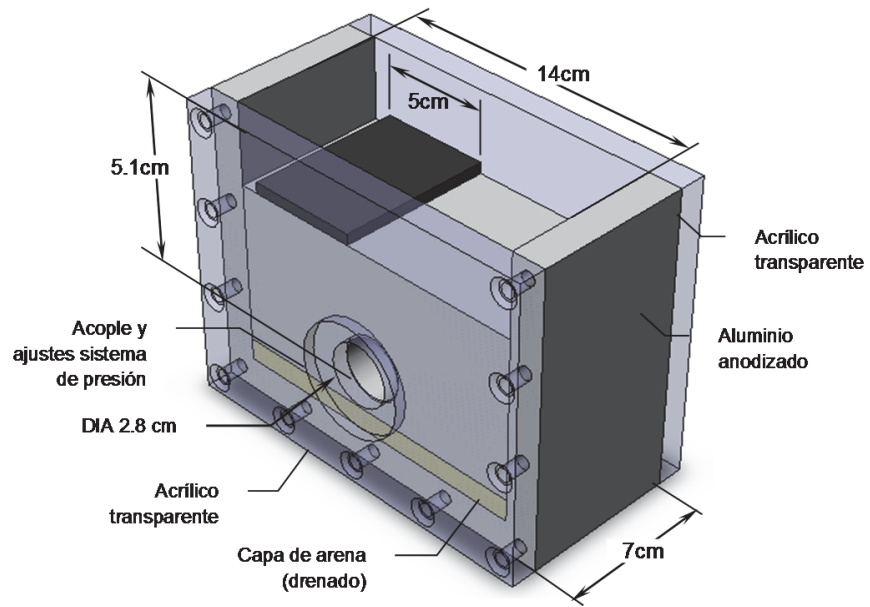

Figura 3. Dimensiones para construcción del modelo. Fuente: Los Autores

Al aplicar los factores de escala geométrica sobre el modelo dentro del rango de funcionamiento de la centrífuga geotécnica, se tiene que con aceleraciones inferiores a $150 \mathrm{~g}$, el modelo debe tener unas dimensiones superiores al de la canasta disponible (profundidad del túnel superior a $10 \mathrm{~cm}$ ) y superiores a $250 \mathrm{~g}$ el diámetro necesario del túnel es inferior a $2 \mathrm{~cm}$, con lo cual lo hace muy difícil de instrumentar. La selección de la escala de $200 \mathrm{~g}$ genera la necesidad de construir un modelo como el mostrado en la Fig. 3.

Al escalar la placa planteada en el problema se tiene que se debería construir una lámina de concreto de $5 \mathrm{~cm}$ por $3.33 \mathrm{~mm}$ de concreto, esa estructura es inviable de ser construida. Según las leyes de escala para deformaciones en estructuras, si se hace un cambio en el material a usar en el modelo, se debe mantener el producto del módulo de elasticidad (E) e inercia (I) igual entre el material que se usa en el prototipo y el del modelo [11]. Por lo tanto se debe mantener la siguiente relación:

$$
E_{C} I_{C}=E_{M} I_{M}
$$

Esto implica que se debe buscar materiales que puedan cumplir las condiciones de inercia y módulo de elasticidad, de tal forma que tengan unas dimensiones viables. Este proceso

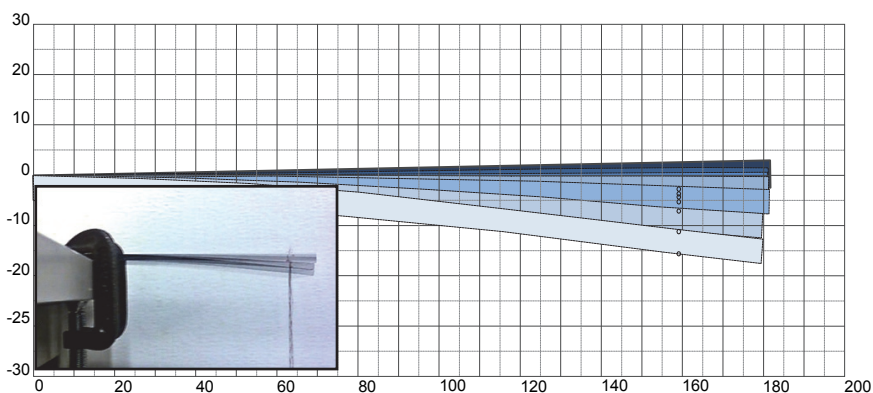

Figura 4. Determinación de módulo de elasticidad por análisis fotográfico de deflexión máxima de viga en voladizo.

Fuente: Los Autores

induce al estudiante a realizar ensayos propios como cálculo de módulo de elasticidad como el mostrado en la Fig. 4.

El estudiante mediante el uso de una cámara digital (como su celular), un soporte y sistema de carga controlada (pesos fijos identificados), es posible generar una viga en cantiléver que se flexiona por la carga aplicada. Las imágenes tomadas por la cámara pueden ser procesadas, obteniendo la curva de deformación máxima vs carga. Con una relación matemática sencilla basada en la geometría de la viga y deflexión máxima, es posible realizar una regresión lineal para obtener el módulo de elasticidad. Para el planteamiento del problema resulta como material adecuado el acrílico comercial con un espesor $5 \mathrm{~mm}$.

\subsection{Preparación del suelo}

El material utilizado para la preparación del suelo del modelo, corresponde a una mezcla de arcillas saturadas: $40 \%$ de bentonita y $60 \%$ de caolín. La preparación de la mezcla de suelo se realizó en una mezcladora industrial. El proceso de mezcla se realiza en seco las dos arcillas en las proporciones necesarias, adicionando agua hasta 1.5 veces el limite liquido de la mezcla [12].

El proceso de consolidación se realiza dentro de la canasta del modelo, garantizando la salida del exceso de agua. Para ello se crea una base de arena y un agujero de salida. Además la placa de consolidación es porosa para permitir la salida del agua. El proceso para determinar si la consolidación ha concluido es mediante el método de Asaoka [11].
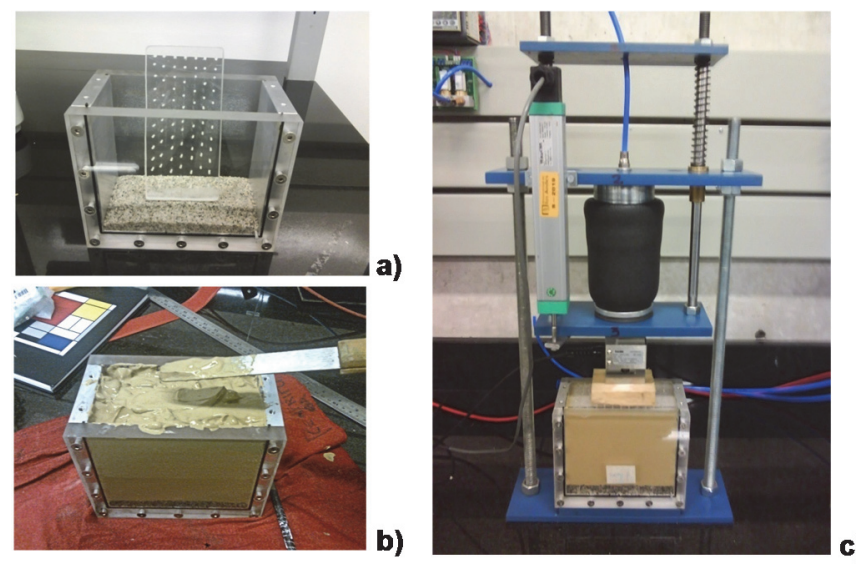

Figura 5. a) Sistema para liberación de exceso de fluido, b) Proceso de construcción del modelo y c) consolidación por prensa neumática. Fuente: Los Autores 

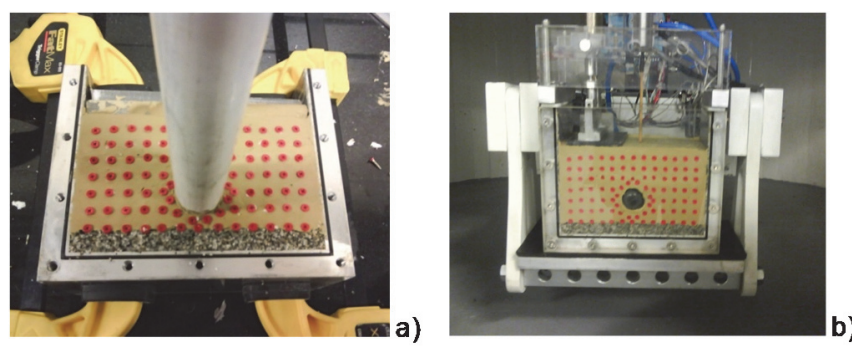

Figura 6. a) Generación de grilla de control y b) instrumentación del modelo montado sobre la centrifuga geotécnica.

Fuente: Los Autores

\subsection{Instrumentación del suelo}

Para controlar la deformación interna del suelo, se incrustaron sobre una de las caras del modelo marcadores de color con alto contraste con respecto al suelo. Estos marcadores se constituirán en el sistemas principal de monitoreo de la estructura, con ellos es posible obtener las deformaciones relativas del modelo al ser grabados mediante una cámara de alta resolución, para luego ser procesado por un software. Además se instaló un sensor de deformación (LVDT) en el eje del túnel con el objetivo, de obtener el asentamiento máximo del modelo, que puede ser fácilmente comparable con el asentamiento que predice la teoría para el prototipo (aplicando las leyes de escala).

\section{Resultados}

El proceso de ensayo consiste en aplicar una presión de confinamiento dentro del túnel mediante una membrana y aire a presión, con el objetivo que no colapse durante el ensayo. Luego a medida que se va incrementando paulatinamente la aceleración centrifuga del modelo, se va incrementando de igual manera dentro del túnel, siguiendo las leyes de escala.

Una vez se llega hasta la aceleración centrifuga final (escala modelo), se aplica la carga que simula la estructura civil en la superficie. Luego se procede a reducir la presión dentro del túnel, con lo cual se inicia la simulación de la excavación del túnel, hasta llegar al desconfinamiento completo y derrumbe de la estructura. En la Fig. 7 se puede observar diferentes fotogramas del video de un ensayo típico.

La Fig. 8 muestra el resultado final del proceso de colapso de la estructura. Usando un software especializado, es posible identificar los puntos de control instalados al inicio de la prueba, para luego poder calcular los vectores de desplazamiento del suelo. Esta información es muy útil para los estudiantes pues pueden ver como la teoría y la práctica convergen, pero al mismo tiempo se alejan un poco en algunos aspectos. Por ejemplo mientras que se ve claro que la curva de desplazamiento tiene una forma de campana invertida de Gauss y esta descentrada (con respecto al eje del túnel) por efecto de la estructura (carga) externa, como lo predice la teoría [14]. El ensayo de centrifuga muestra un colapso no homogéneo del túnel debido a las no linealidades presenten en el modelo, como lo son: fricción cara transparente del contenedor con el suelo, problemas de consolidación no homogénea, efecto local de la instrumentación instalada, entre otras.

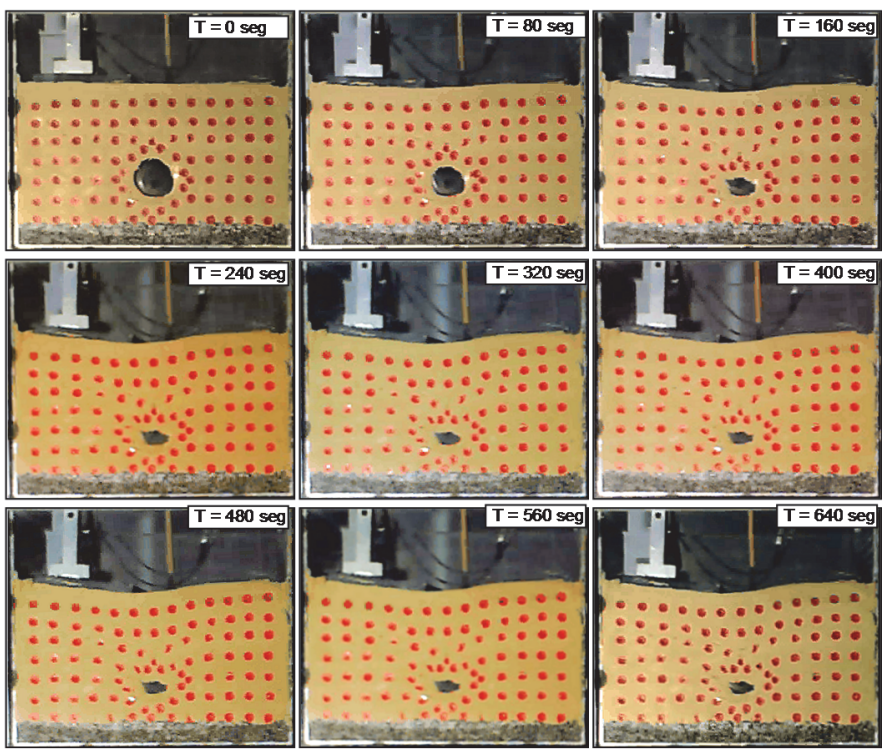

Figura 7. Fotografías en diferentes tiempos de falla del túnel en el modelo. Fuente: Los Autores
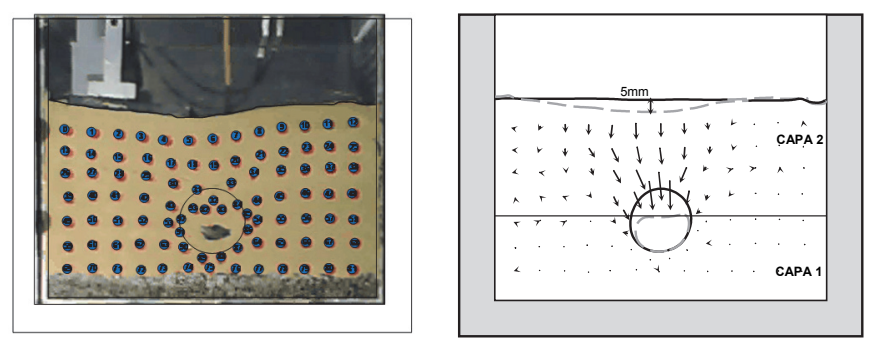

Figura 8. Izq. Fotografía de falla final del modelo y Der. Vectores de movimiento del suelo en modelo.

Fuente: Los Autores

\section{Discusión}

Los resultados obtenidos por los estudiantes en pruebas de laboratorio como el descrito, permiten consolidar conocimientos no solo del problema principal planteado, sino también de una serie importante de conocimientos previos que generalmente corresponden a: origen de los suelos, estructura de los suelos, procesos de consolidación, caracterización de suelos en laboratorio, suelos saturados y no saturados, instrumentación, etc.

La alternativa de laboratorio para procesos tan complejos como el mostrado seria la creación de modelos a escala real o de obras reales. Esto conllevaría mucho tiempo, riesgos laborales altos y costos muy elevados, haciéndolo imposible de realizar por un grupo de estudiantes. Pese al alto costo inicial de instalación de este tipo de laboratorios es alto, pero el campo de aplicación en geotecnia es muy amplio, tanto en docencia (caso de aplicación mostrado en el presente documento) como en investigación.

Las prácticas de laboratorio han probado de manera contundente que son fundamentales para la apropiación del conocimiento por parte de los estudiantes, tal como lo muestra el modelo Kolb. 
Pese a que los laboratorios se han empezado a sustituir en la educación superior por sistemas virtuales, es importante tener claro que una simulación numérica, sin importar el nivel de complejidad, siempre tendrá una serie de suposiciones para acotar el problema y encontrar una solución. Esa simplificación hace que la solución obtenida en el laboratorio virtual y la teoría aprendida en clase sea idéntica, generando que el estudiante olvide o nunca tenga en cuenta las simplificaciones originales del modelo matemático, al igual de la incertidumbre y falta de conocimiento completo de los problemas de ingeniería real. Los laboratorios con modelos a escala en cambio, pese a que tienen un ambiente controlado siempre tendrán un nivel de incertidumbre inherente, el cual el estudiante mediante la teoría y la práctica realizada tendrá que identificar, cuantificar y analizar.

\section{Conclusiones}

Los laboratorios en ingeniería son fundamentales para garantizar que los estudiantes se apropien del conocimiento descrito en la teoría en el desarrollo del curso.

Las prácticas reales tienen ventajas sobre las virtuales, debido a que las primeras tienen un grado de semejanza más cercano al mundo real, permitiendo una etapa de análisis por parte de los estudiantes mucho más fuerte.

Los modelos geotécnicos en centrifuga conllevan un tiempo importante de ejecución, por lo cual deben tener un proceso importante de planeación, que incluyen disposición de equipos y trabajo supervisado de los estudiantes.

Para la construcción de obras geotécnicas se puede tener acceso a una serie de métodos presentes en la literatura que generan cálculos que describen el comportamiento. Sin embargo resulta fundamental, poder reproducir las condiciones naturales en el laboratorio para posteriormente verificar su comportamiento teórico. Esto derivará en reducir la brecha de incertidumbre que se genera cuando se realizan obras civiles de alta envergadura como lo son los túneles poco profundos.

La posibilidad de escalar el tiempo en los modelos en centrifuga geotécnica, permite que se puedan realizar videos donde se puede analizar el comportamiento temporal o ante cambios en las condiciones de carga, de gran importancia didáctica.

\section{Agradecimientos}

El autor desea expresar su agradecimiento a la Universidad de Los Andes por permitir la utilización de sus equipos de laboratorio. De igual manera al ingeniero Bernardo Caicedo por su apoyo científico para el desarrollo del presente proyecto.

\section{Referencias}

[1] Shuman, L., Besterfield-Sacre, M. and Mcgourty, J., The ABET "Professional Skills" - Can they be taught? Can they be assessed?, Journal of Engineering Education, 9481), pp. 41-55, 2005.

[2] Chrobak, R. The globalization and the engineering teaching for the XXI Century. Primer Congreso Argentino de Enseñanza en la Ingeniería. Río (Córdoba), Argentina, 1996.
[3] Hadim, H., Donskoy, D., Sheppard, K., Gallois, B. and Nazalewicz, J., Teaching mechanics to freshmen by linking the lecture course to a design course, ASEE Conference Proceedings Search, 2000.

[4] Caro, S. y Reyes, J., Prácticas docentes que promueven el aprendizaje activo en Ingeniería Civil, Revista de Ingeniería, 18, pp.48-55, 2003.

[5] Ruiz, D., Magallón, J. y Muñoz, E., Herramientas de aprendizaje activo en las asignaturas de ingeniería estructural, Ingeniería y Universidad, 10(1), pp.97-115, 2006.

[6] Fernández-Sánchez, G. and Millán, M., Structural analysis education: Learning by hands-on projects and calculating structures, Journal of Professional Issues in Engineering Education \& Practice, 139(3), 2013.

[7] Kolb, D. and Fry, R., Toward an applied theory of experiential learning, in C. Cooper (ed.), Theories of Group Process, London: John Wiley, 1975.

[8] Sharp, J., Harb, J. and Terry, R., Combining Kolb learning styles and writing to learn in engineering classes, Journal of Engineering Education, 86(2), pp.93-101, 1997.

[9] Feisel, L. and Rosa, A., The role of the laboratory in undergraduate engineering education, Journal of Engineering Education 94(1), pp. 121130, 2005.

[10] Wartman, J, Geotechnical physical modeling for education: Learning theory approach, Journal of Professional Issues in Engineering Education and Practice, 132(4), 2006. DOI: 10.1061/(ASCE)10523928(2006)132:4(288)\#sthash.lfCu3e7j.dpuf

[11] Taylor, R., Geotechnical centrifuge technology, Blackie Academic \& Professional, London, 1995.

[12] Vargas, J., Modelación física en centrífuga, de un muro pantalla apuntalado en suelos blandos de Bogotá, Tesis, Universidad de los Andes, Bogotá, Colombia, 2003.

[13] Caicedo, B., Velásquez, R. and Monroy, J, Modelación física en centrífuga, Tesis, Universidad de los Andes, Bogotá, Colombia, 2004.

[14] Lee, C., Wu, B. and Chiou, S., Soil movements around a tunnel in soft soils, Proc. Natl. Sci. Counc. ROC(A), 23(2), pp. 235-247, 1999.

J.A. Tristancho-Ortiz, es Ing. mecánico de la Universidad Nacional de Colombia, MSc. en Ingeniería Electrónica y de Computadores, y Dr. en Ingeniería de la Universidad de Los Andes, Colombia. Profesor asistente de la Universidad Distrital Francisco José de Caldas desde 2011. Investigador del grupo DIMSI. Áreas de investigación: Automatización Industrial, Simulación y modelamiento físico, y diseño de software especializado de ingeniería ORCID: 0000-0002-1471-1052 